\title{
Guest editors' notes
}

This special issue has nine papers selected from the Africa Regional Workshop at Makerere University (Kampala, Uganda) on January 11th to 13th 2021.

The first two papers relate to Research Data Management (RDM). The first one analyses the authorship, volume, visibility, and quality of publications on RDM in Sub-Saharan Africa. The analysis was done using bibliometrics focusing on RDM publications from, and on, Sub-Saharan Africa which are currently indexed in Google Scholar.

The second article presents available open RDM resources for different data practitioners, particularly researchers and librarians at the University of Dodoma, in Tanzania. Some of the RDM resources discussed in this paper are Data Management Plan (DMP) and a data repository available for researchers to freely archive and share their research data with the local and international communities.

The third paper highlights the data-sharing attitudes and behaviors of African data curators and data management experts. The paper compares data from an earlier study and analyses the new findings between the data sharing attitudes and behaviors between Africans and non-Africans.

The fourth paper articulates the data literacy integration agenda and how it can catalyze the achievement of Sustainable development goals. The paper unpacks the role of data literacy in catalyzing the achievement of the Sustainable Development Goals (SDGs), challenges faced, and suggests recommendations to the challenges. It is however sad to note here that the author of this paper recently passed on 15th December 2021. May the good lord accord Gorreti an eternal rest.

The fifth paper discourses the establishment of a data center at Mzuzu University Library in Malawi after the unfortunate fire outbreak of 2015 that destroyed the whole library. Interesting models are drawn in the paper like; the six-month process of restoring an interim library and the designing \& construction of the new library in collaboration with the Virginia Technological School of Architecture \& Design in the United States.

The sixth paper goes further to examine the growth and development of institutional repositories in the East African Countries of Kenya, Tanzania and Uganda. The paper contextualizes and discusses in detail the drivers and barriers to the development of institutional repositories in East Africa such as: policy formulation, financial support, training, infrastructure, open access awareness among others.

The seventh paper focuses on the learning outcomes in literacy and numeracy in Uganda in the light of maternal education. In this paper, deeper analysis was conducted on the data mined from the Uwezo assessment data to show the effect of the mothers' education on the numeracy and literacy learning outcomes among children in Uganda.

The eighth paper illuminates the opportunities and risks of sharing agricultural research data in Tanzania. Stimulating themes on sharing of research data are developed and discussed in this paper such as: research collaboration, transparency, accuracy, funding, policy, institutional, and government support among others.

Finally, the ninth and last paper narrates the data dissemination process at the Uganda Bureau of Statistics (UBOS). The paper presents in detail the methods, channels of data sharing such as: 
workshops, websites, libraries, resource centres, social media, and the physical delivery of print resources to the UBOS partners and clients.

Winny Nekesa Akullo and Robert Stalone Buwule 